\title{
PARASTTES OF RUMINANTS IN THE JACKSON HOLE AREA: SCARABAEOID BEETLES ACTING ON LUNGWORM, DICTYOCAULUS hadweni, LARVAE IN ELK AND CATTLE FECES 1982
}

\author{
Robert ¿. Bergstrom \\ Division of Microbiology and Veterinary Medicine \\ University of Wyoming \\ Laramie
}

Lungworm of elk, Dictyocaulus hadweni (syn: D. vivparus) was first designated as Strongylus filaria in elk and red deer, (Blair, 1903) and lungworm was then and in 1905 reported to cause bronchopneumonia in elk. (Blair 1905). Records of lungworm in elk in Yellowstone and the Tetons were rather incomplete until Rush (1932), Mills (1936), Alderson (1951), Murie (1951) and others listed internal parasites Lound in elk. It is surprising that Mills did not find $\underline{D}$. hadweni in 100 elk taken from the Yellowstone herd.

It is interesting to note that a high percentage of the elk in Teton National Park are pasitive for lungworm in the spring. Fewer elk are infected in the summer and fall when the vegetation is usually sufficiently good to allow the elk an abundance of food and a resultant physiological condition that is excellent.

Perhaps elk serum proteins are somewhat low in the April-May period when the physiological "low" is reached by the elk. The lack of immunoglobulins may, in part, explain the high prevalence of lungworm infections in elk of the Tetons during early spring months.

\section{Objectives}

The objectives of the present study are:

1. Continue research of the prevalence of Dictyocaulus hadweni in Teton elk during four seasons of the year. (This must be done to find worm-positive elk for the biological predation research.) The search has been extended to elk in Yellowstone National Park during the past 2 years and will be continued;

2. Check, via fecal analyses, for larvae spring-summer and winter and by lung dissections (adult worms) and/or by fecal analyses during the fall for relative numbers of the parasite/elk;

3. Experiment in the laboratory for the effect of Aphodius spp. Canthon sp., other Scarabaeoid beetles against 1st stage larvae of Dictyocaulus sp; and 
4. Extend field observations to include the action of Aphodius spp. on Dictyocaulus larvae in or on elk feces. (This portion is very time consuming due to the fact that the investigator does not, beforehand, know which elk are positive for the worm.)

\section{Methods}

Fecal analyses were conducted by the use of a jet of water played over 6-100 g of elk fecal pellets in a plastic petri dish. After the water had wetted the pellents, the larvae were allowed 10-20 minutes to move off the pellets. The pellets were again rinsed by a jet of water after which the pellets were removed from the dish by sterile forceps. Dictyocaulus larvae were counted in the sectioned petri dishes via dissecting scope at $45 \mathrm{X}$. Prevalence ( 8 of elk positive for lungworm larvae) and the number of larvae were noted.

During the fall hunting season, elk lungs were gathered by the National Elk Refuge personnel, by the researcher, but primarily by Teton Park rangers. Elk lungs were checked for the presence of adult Dictyocaulus worms by use of bandage scissors as pneumotomes in order to lay open all major bronchioles. With light infections, worms were found in the smaller bronchioles near the periphery of the lobes of the lungs while larger numbers of worms, larger bronchioles were partially or completely filled with worms up to and including the area of the main bifurcation of the trachea.

Worms were collected, sexed, counted, and in some cases, fixed for preservation.

\section{Results}

Percent of elk positive for Dictyocaulus sp. (presumable D. hadweni) was similar to the prevalence in May 1980 or $63 \%$ if one uses data from both sexes. However, about $85 \%$ of the "wet" or pregnant cows were positive at the same time in May 1982.

Prevalence in the Teton elk had dropped to about $32 \%$ by late August.

Gibbon River elk in Yellowstone National Park experienced similar prevalences of lungworm infection with a high prevalence in spring and about $35 \%$ positive by late August.

Yearling cattle on two ranches north and northeast of Dubois in Fremont County carried low numbers of Trichostrongylid worms and only 1 of 13 yearling steers on elk range at about 9,000 feet elevation was positive for Dictyocaulus sp. lungworm larvae in feces. Twelve steers from another ranch were not infected with lungworm according to the limited survey material.

Data sumarized in Figures 1 and 2 show the prevalence of lungworm infections in Teton elk and Fremont county cattle during the summer of 1982. The numbers of cattle sampled were too low for statistical validity but did show an infected 


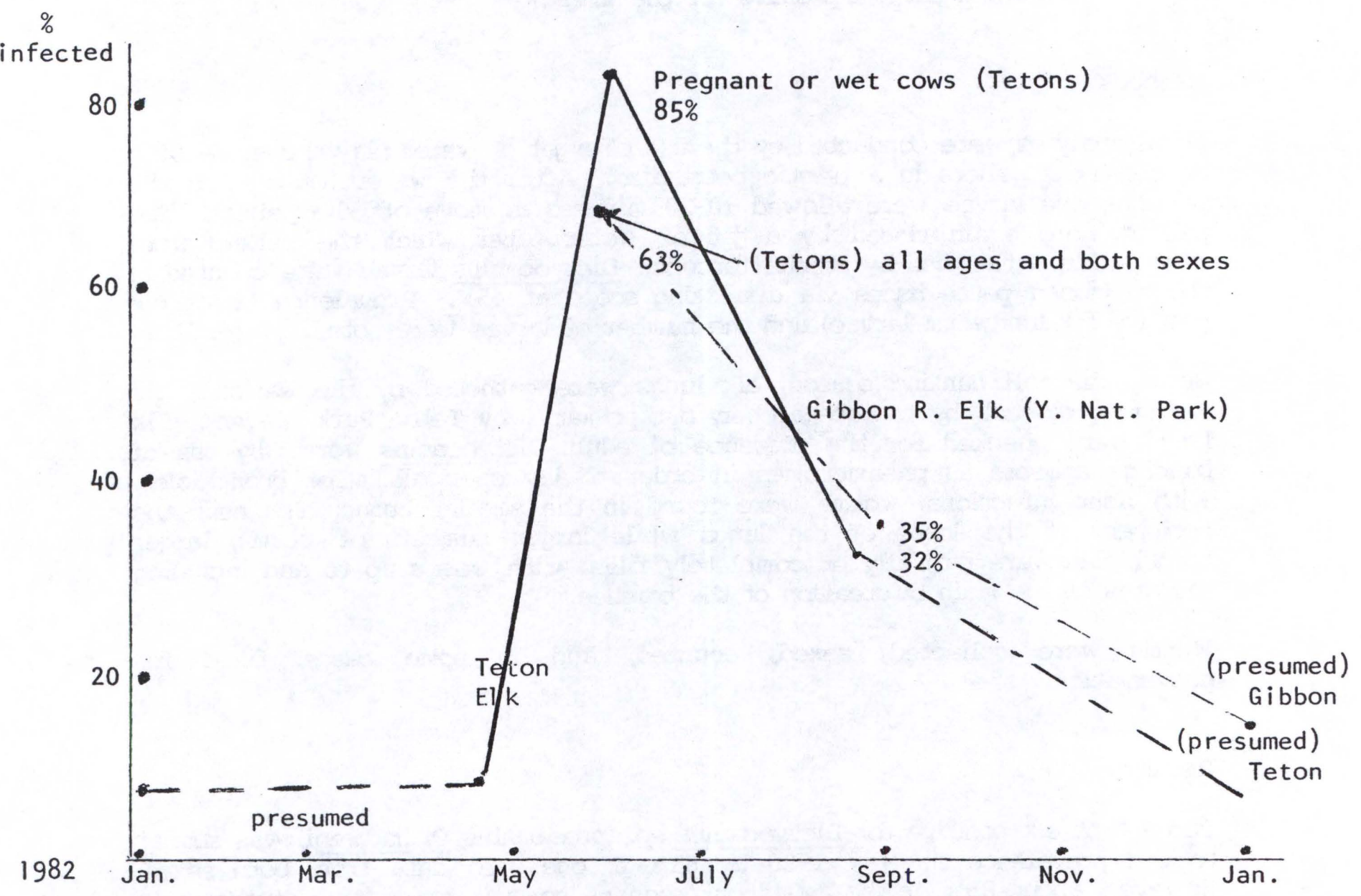

Fig 1. Prevalence of Dictyocaulus-positive elk. Teton Park and Gibbon R. meadows Y.N. Park, Wyo.

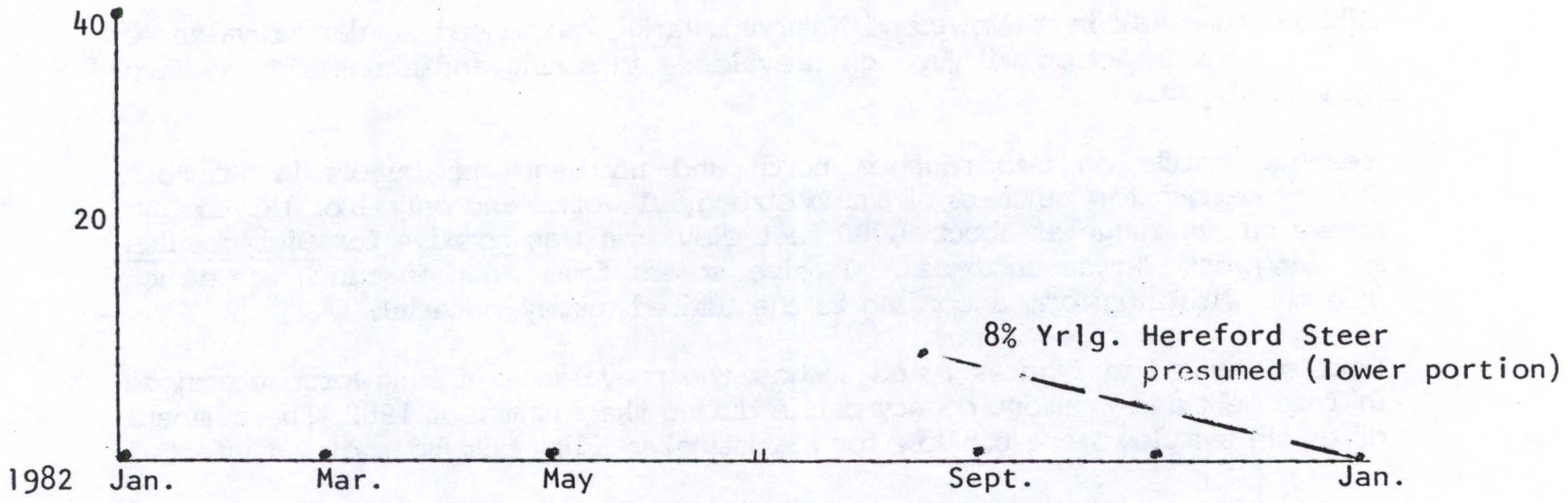

Fig. 2. Prevalence of Dictyocaulus-Positive Cattle Northeast of Dubois, WY in Elk Range 
yearling steer in a herd that was sampled randomly. Such findings would point to a need for further research of bovids and elk/deer on forest

Service permit lands for the prevalence of lungworm in both bovids and cervids.

Aphodius spp. beetles were active by May 17, 1982. Laboratory experiments with Aphodius spp. interacting with Dictyocaulus sp. larvae (first stage) were conducted as during the previous 3 years. Laboratory results of beetles-Dictyocaulus larvae interaction showed mean decreases in Dictyocaulus populations in laboratory trials of $68 \%$. That figure is similar to those of previous years shown in Table 1.

\section{Discussion}

Teton elk left the National Elk Refuge during late April-early May, 1982.

The season was 2 weeks late due to snow depth and cool weather in April. Vegetational growth was slow until late May in Teton Park. Elk condition was moderate-poor and nearly $85 \%$ of the pregnant cows were positive for lungworm by May 25. Five and 6-point bull elk were 2 weeks late in appearance.

Elk left the Lamar meadows in Yellowstone Park in early July, 10-15 days later than in the 1961-1963 period.

The new research portion of ruminant lungworm problems was useful since a lungworm larva was found in a yearling bovid ranging on Forest Service permit range northeast of Dubois. Such range. is also utilized by elk for large portions of the year.

Only a limited number of trials was conducted with beetles during 1982 . The range of decimation of Dictyocaulus numbers was 23-100\% with a mean of $68 \%$. These data compare favorably with the mean of 5 previous years $(1976-80)$ or 84.7\%, Table 1 .

\section{Conclusions}

1. As in past years, a high prevalence of elk were positive for lungworm in May 1980. A mild winter and early spring allowed elk to move off the National Refuge early.

2. Gibbon River elk (Y.N.P.) show as high or higher prevalence of Dictyocaulosis than do the elk at Jackson, Wyoming.

Work Planned: 1983

(See proposal, 1983, with revision of the previous objectives and new portions includiing possible bovid-cervid lungworm cross-transmission. 


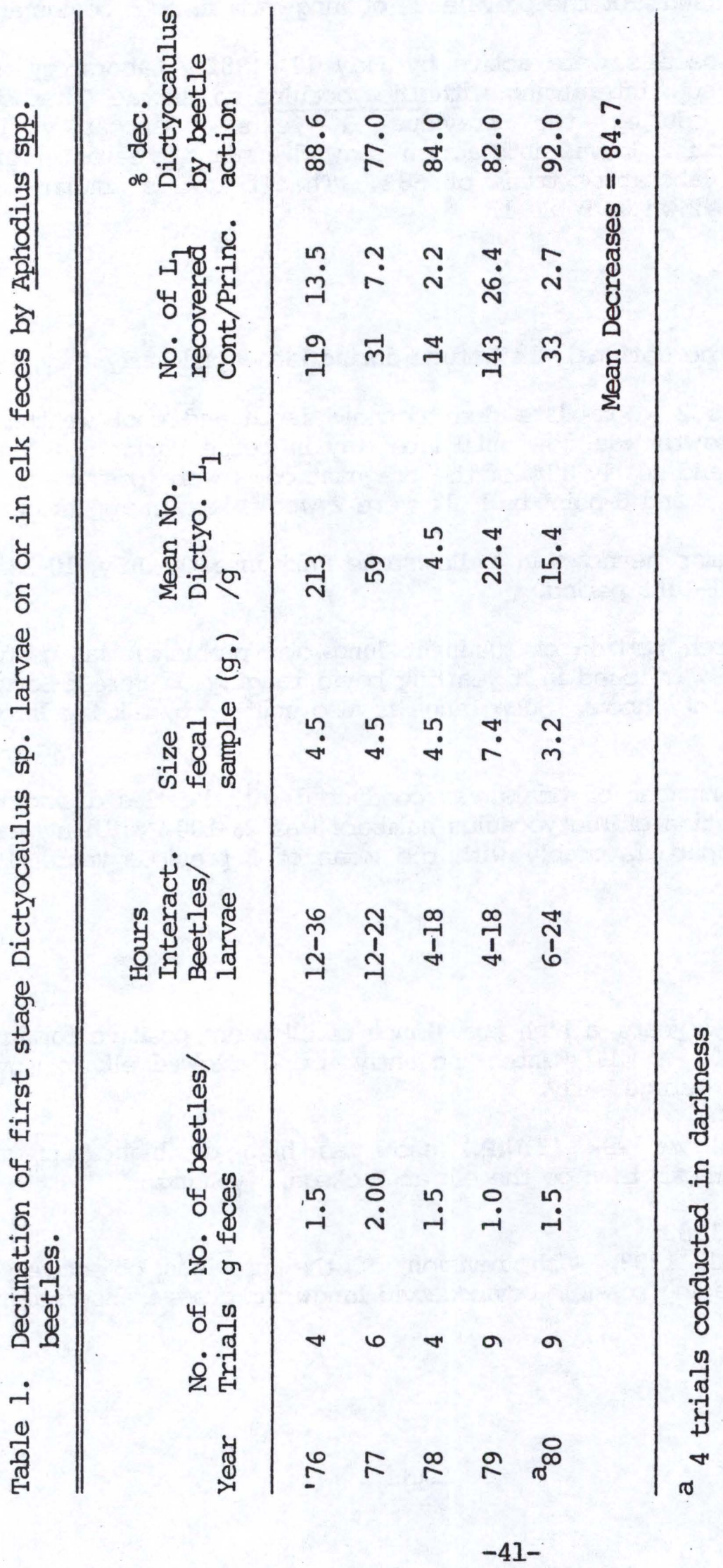




\section{Iiterature Cited}

Bergstrom, R. C. 1975. Prevalence of Dictyocaulus viviparus, infections in Rocky Mountain elk in Teton Co., Wyoming. J. Wildl. Dss. 8:57-62.

Blair, W. R. 1903. Internal parasites in Wild Animals. 8th Ann. Report, New York Zool. Soc. 1905. Report of the Medical department. 10th Ann. Rept., N.Y. Zool. Soc. pp. 138-143.

Mills, H. B. 1936. Observations on Yellowstone elk. J. Mammal. 17(3):250-253.

Murie, O. J. 195l. The elk of North America. The Stackpole Co., Harrisburg, PA. and Wildl. Mgmt. Inst, Wash., D.C. 376 pp.

Rush, W. J. 1932. Northern Yellowstone elk study. MT Fish and Game Comm., Helena. 131 pp.

\section{Acknowledgements}

Thanks are extended to personnel of the National Elk Refuge, and to the rangers and Mr. Robert Wood of the Teton National Park Service. The use of laboratory facilities and lodging at the U.W.-N.P.S. Research Center and Dr. Diem's cooperation and counsel in the research effort is appreciated. 